\title{
RATE OF MALIGNANT BREAST CANCER AMONG WOMEN WITH BREAST MASS ATTENDING ALDEWANIYAH TEACHING HOSPITALS: A CROSS-SECTIONAL STUDY
}

\author{
HASSAN RAJI JALLAB ${ }^{1 *}$ \\ ${ }^{1}$ Department of Family and Community Medicine, College of Medicine, University of Al-Qadisiyah, Iraq. \\ Email: Hassan.jallab@qu.edu.iq
}

Received: 27 August 2018, Revised and Accepted: 19 September 2018

\begin{abstract}
Objective: The problems of breast mass, pain, or discharge are extremely common in the Iraqi population, as well as, globally. However, the trend in most health-care institutions is that most breast lesions are of benign biologic behavior and among true neoplastic lesions. Marital status has been linked to the outcome of breast malignancy; however, the link is controversial.Thus, the aim of the present study is to make a clear insight into the true incidence rate of carcinoma and their risk factors.

Materials and Methods: The study was designed to be a cross-sectional study involving a cohort of 182 Iraqi women with the breast mass. Patients were selected in a systemic random way from the population of patients already visiting the surgical consultation clinic and ward and oncology unit in Al-Dewaniyah teaching hospital in Al-Diwaniyah province, Iraq.

Result: The present study showed that the most breast lesions (82\%) were benign, and the most frequent one was a fibroadenoma (37.4\%). Malignant lesions accounted for a small percentage (17.4\%). Mean age of patients with carcinoma was $49.78 \pm 7.58$ years and most all cases occurred after 20 years of age and that $87.5 \%$ of cases were seen after the age of 40 . Majority of breast carcinoma were of invasive ductal carcinoma. No significant association was seen between the clinical behavior of breast mass and marital status; however, malignant clinical behavior showed significant association with age.
\end{abstract}

Conclusion: The incidence rate of malignant breast lesions in Iraqi women with breast mass is similar to that seen worldwide and that age is the main risk factor that predicts the malignant clinical behavior of a breast mass.

Keywords: Breast cancer, Marital status, Iraq.

(C) 2019 The Authors. Published by Innovare Academic Sciences Pvt Ltd. This is an open access article under the CC BY license (http://creativecommons. org/licenses/by/4. 0/) DOI: http://dx.doi.org/10.22159/ajpcr.2018.v11i12.29342

\section{INTRODUCTION}

In daily clinical practice, the problems of breast mass, pain, or discharge is extremely common in the Iraqi population, as well as, globally [1]. Nearly all patients develop fear about the possibility of malignancy when they acquire a breast mass. However, the trend in most healthcare institutions is that most breast lesions are of benign biologic behavior, and among true neoplastic lesions, the rate of malignancy is somewhat low [2]. The most common form of malignant breast lesions is of epithelial origin, namely carcinoma. The risk of developing breast carcinoma has a positive correlation with age, being rare before the age of 25 , the incidence rate becoming increasing greater after 25, and majority of cases are diagnosed after the age of 50; the median age at diagnosis is around 65 years old [3]. Unfortunately, a substantial amount of data suggested that Iraqi women showed the younger age of acquiring breast cancer and that the rate of breast carcinoma during the past two decades outnumbered that of the preceding decades. The increasing incidence has been linked by many authors to the first, second, and third Arab Gulf Wars, during which the exposure to chemical weapons and radiation-based weapons is blamed to be number one risk factor [4]. For most surgeons, the histological report of a breast mass is the main step in making the decision about the nature of breast mass. From histological point of view, benign breast lesions can be inflammatory such as breast abscess and duct ectasia, proliferative, such as fibrocystic disease and fibroadenoma, and reactive conditions such as fat necrosis; whereas most malignant lesions are epithelial in origin, ductal carcinoma is the most frequent and accounts for approximately $80 \%$ of the cases. Lobular carcinoma comes next and accounts for $<20 \%$ of the cases [5]. Both ductal carcinoma and lobular carcinoma can be infiltrative or non-infiltrative lesions [6]. In addition to advancing age, other risk factors are blamed to participate in the causation of breast carcinoma, including hormonal imbalance, especially excess estrogen exposure, obesity, alcohol intake, lack of exercise, women who got married late and depends on exclusive bottle feeding are also at higher risk, exposure to chemical agents and radiation, and the list of risk factors includes several other controversial suggestions [7]. The present study was designed to be a cross-sectional study that included a cohort of Iraqi women with various breast lesions to make a clear insight about the true incidence rate of carcinoma and risk factors associated with the development of malignant breast lesions.

\section{PATIENTS AND METHODS}

The study was designed to be a cross-sectional study involving a cohort of 182 Iraqi women with the breast mass. Patients were selected in a systemic random way from the population of patients already visiting the surgical consultation clinic and ward and oncology unit in AlDewaniyah teaching hospital in Al-Diwaniyah province/Iraq. The beginning of data collection was dated the $20^{\text {th }}$ January 2018 and ended on $10^{\text {th }}$ June 2018 . The questionnaire form was based on the following:

- Sociodemographic characteristics of patients: Mainly age and marital status.

- Review of histopathological features including histological type, biological behavior (benign vs. malignant), grade, and stage of malignant tumors.

Data were collected, summarized, analyzed, and presented using two software programs; these were the Statistical Package for the Social Sciences version 23 and Microsoft Office Excel 2013. Numeric variables 
were presented as mean, standard deviation, and range, whereas categorical variables were expressed as number and percentage. The incidence rate of depression was expressed as a percentage. Association between categorical variables was assessed using either Chi-square test or Yates correction for continuity when more than $20 \%$ of cells have expected counts $<5$. Comparison of mean values between the three groups was done using oneway analysis of variance. The level of significance was considered at $\mathrm{p} \leq 0.05$.

\section{RESULTS}

This study included 182 cases of breast lesions in women with an age range of 16-72 years and a mean age of $38.79 \pm 12.74$ years. Taking marital status into consideration, 150 (82.4\%), whereas, 32 (17.6\%) were unmarried. The breast lesion was situated on the right side in $85(46.7 \%)$, in the left side in 76 (41.8\%), and bilateral in $21(11.5 \%)$. According to clinical behavior, 150 (82.4\%) had benign lesions and $32(17.6 \%)$ had malignant lesions, as shown in Table 1.

Of 182 patients, 68 had fibroadenoma constituting $37.4 \%$ of all samples included in the present study and $45.3 \%$ of benign cases enrolled in the current study. 21 had fibrocystic disease constituting $11.5 \%$ of all sample included in the present study and $14.0 \%$ of benign cases enrolled in the current study. 44 had inflammatory lesions in the form of mastitis, duct ectasia, and abscess forming $24.2 \%$ of all samples included in the present study and $29.3 \%$ of benign cases enrolled in the current study. Seventeen cases had simple cyst accounting for $9.3 \%$ of all samples included in the present study and $11.3 \%$ of benign cases enrolled in the current study, as shown in Table 2. Of 182 patients, 3 had carcinoma in situ constituting $1.6 \%$ of all sample included in the present study and $9.4 \%$ of malignant cases enrolled in the current study. 24 had invasive ductal carcinoma constituting $13.2 \%$ of all sample included in the present study and $75.0 \%$ of malignant cases enrolled in the current study. Four had invasive lobular carcinoma forming $2.2 \%$ of all sample included in the present study and $12.5 \%$ of malignant cases enrolled in the current study. One case had medullary carcinoma accounting for $0.5 \%$ of all sample included in the present study and $3.1 \%$ of malignant cases enrolled in the current study, as shown in Table 3.

\section{Table 1: General characteristics of the study sample}

\begin{tabular}{ll}
\hline Characteristic & Value \\
\hline Number of cases & 182 \\
Age & \\
Mean \pm SD (years) & $38.79 \pm 12.74$ \\
Range (Min.-Max.) (years) & $56(16-72)$ \\
Marital status, n (\%) & $150(82.4)$ \\
Married, n (\%) & $32(17.6)$ \\
Unmarried, n (\%) & \\
Site & $85(46.7)$ \\
Right, n (\%) & $76(41.8)$ \\
Left, n (\%) & $21(11.5)$ \\
Bilateral, n (\%) & \\
Clinical behavior & $150(82.4)$ \\
Benign, n (\%) & $32(17.6)$ \\
Malignant, n (\%)
\end{tabular}

SD: Standard deviation; Min.: minimum; Max.: maximum; n: number of cases

Table 2: The frequency distribution and rates of benign breast lesions

\begin{tabular}{llll}
\hline Benin lesion & n & $\begin{array}{l}\text { Percentage } \\
\text { of all sample }\end{array}$ & $\begin{array}{l}\text { Percentage of } \\
\text { benign lesions }\end{array}$ \\
\hline Fibroadenoma & 68 & 37.4 & 45.3 \\
Fibrocystic disease & 21 & 11.5 & 14.0 \\
$\begin{array}{l}\text { Inflammatory } \\
\text { (mastitis, duct ectasia, }\end{array}$ & 44 & 24.2 & 29.3 \\
$\begin{array}{l}\text { and abscess) } \\
\text { Simple cyst }\end{array}$ & 17 & 9.3 & \\
Total & 150 & 82.4 & 11.3 \\
\hline
\end{tabular}

n: number of cases
With respect to the grade of malignant lesions, 6 patients had Grade I breast cancer accounting for $18.8 \%$ of all malignant cases included in this study, 19 had Grade II breast cancer constituting $59.4 \%$ of all malignant cases enrolled in the current study, and 7 patients had Grade III breast cancer forming 21.9\% of all malignant cases subjected to the present study, as shown in Fig. 1. According to the stage of disease, the current study included $3(9.4 \%)$ cases at Stage 0 (carcinoma in-situ), $5(15.6 \%)$ cases at Stage I, $15(46.9 \%)$ at Stage II, $7(21.9 \%)$ cases at Stage III, and $2(6.3 \%)$ cases at Stage IV, as shown in Fig. 2.

The following study showed that patients with malignant lesions were significantly older than patients with benign lesions, $49.78 \pm 7.58$ years versus $36.66 \pm 12.4$ years $(\mathrm{p}<0.001)$, as shown in Fig. 3 . The distribution

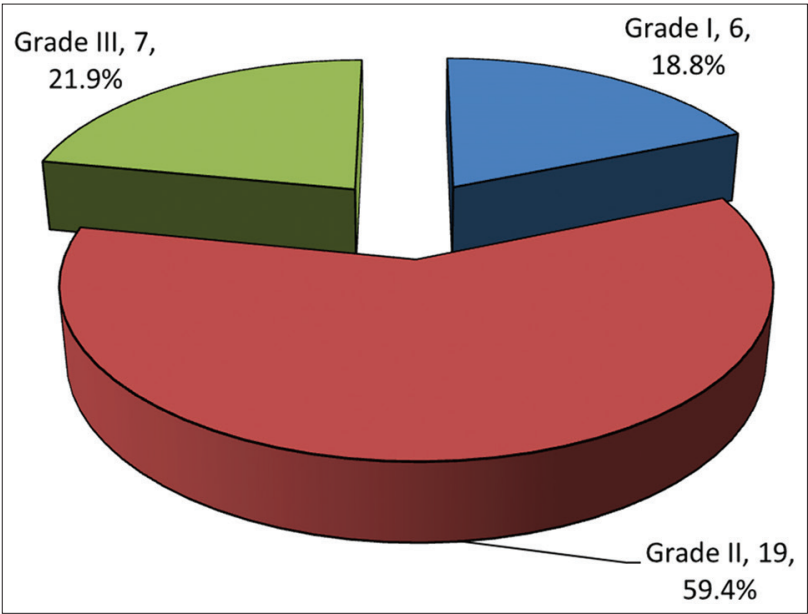

Fig. 1: The distribution of malignant cases according to grade

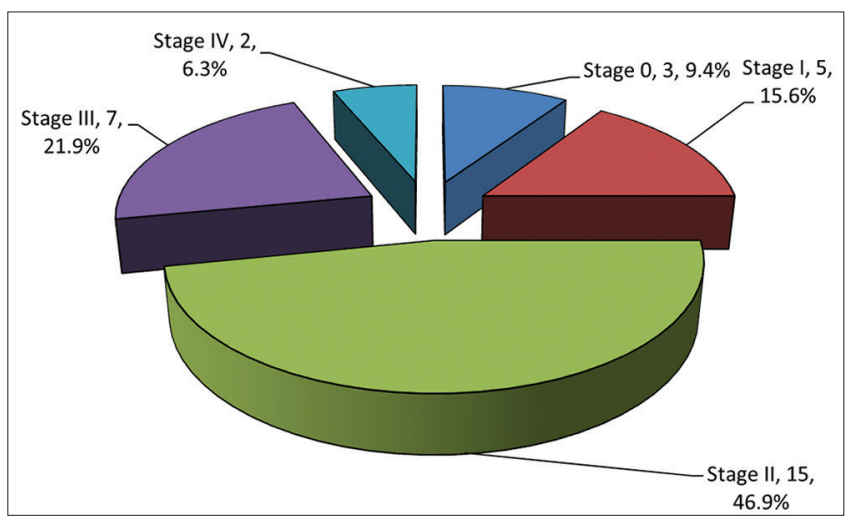

Fig. 2: The distribution of malignant cases according to stage

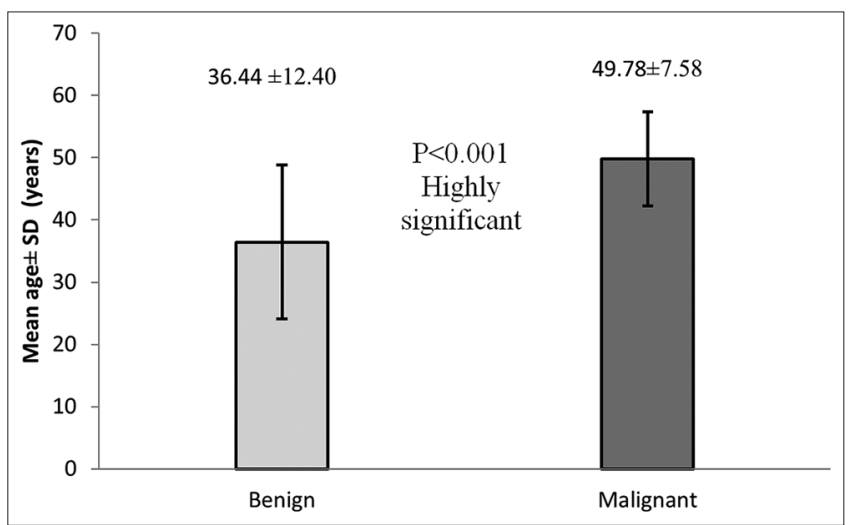

Fig. 3: The difference in mean age between patients with benign breast lesions and patients with malignant breast lesions 
of malignant and benign lesions according to 20 years' intervals is shown in Table 4. There was no significant association between age of patients and type of malignancy $(p=0.779)$, [Table 5]. In addition, there was no significant association between the age of patients and grade of the malignant tumor $(\mathrm{p}=0.842)$, [Table 6].

Moreover, there was no significant association between the age of patients and stage of the malignant tumor $(\mathrm{p}=0.871)$, [Table 7]. There was no significant association between marital status and clinical behavior of breast lesions $(p=0.064)$. In addition, there was no significant association between marital status and type of benign lesions $(p=0.176)$. Added to that, there was no significant association between marital status and type of malignant lesion $(p=0.871)$. Moreover, there was no significant association between grade and stage of malignancy

Table 3: The frequency distribution and rates of malignant breast lesions

\begin{tabular}{llll}
\hline Malignant lesion & $\mathbf{n}$ & $\begin{array}{l}\text { Percentage } \\
\text { of all cases }\end{array}$ & $\begin{array}{l}\text { Percentage of } \\
\text { malignant cases }\end{array}$ \\
\hline CIS & 3 & 1.6 & 9.4 \\
Invasive ductal carcinoma & 24 & 13.2 & 75.0 \\
Invasive lobular carcinoma & 4 & 2.2 & 12.5 \\
Medullary carcinoma & 1 & 0.5 & 3.1 \\
Total & 32 & 17.6 & 100.0 \\
\hline
\end{tabular}

CIS: carcinoma in situ, n: number of cases

Table 4: Association between the clinical behavior of breast lesions and age of the patients

\begin{tabular}{lllll}
\hline $\begin{array}{l}\text { Age } \\
\text { intervals (years) }\end{array}$ & $\begin{array}{l}\text { Benign } \\
\mathbf{n = 1 5 0}\end{array}$ & $\begin{array}{l}\text { Malignant } \\
\mathbf{n}=\mathbf{3 2}\end{array}$ & $\boldsymbol{\chi}^{2}$ & $\mathbf{p}$ \\
\hline$\leq 20$ & $15(10.0)$ & $0(0.0)$ & 33.095 & $<0.001$ \\
$21-40$ & $82(54.7)$ & $4(12.5)$ & & highly \\
$41-60$ & $45(30.0)$ & $27(84.4)$ & & significant \\
$>60$ & $8(5.3)$ & $1(3.1)$ & & \\
\hline
\end{tabular}

and the marital status of patients ( $\mathrm{p}=0.584$ and 0.837 , respectively), as shown in Table 8 .

\section{DISCUSSION}

The present study showed that the most breast lesions (82\%) were benign and that, among benign lesions, the most frequent one was the fibroadenoma (37.4\%). Malignant lesions accounted for a small percentage $(17.4 \%)$. Mean age of patients with carcinoma was $49.78 \pm 7.58$ years and most all cases occurred after 20 years of age and that $87.5 \%$ of cases were seen after the age of 40 . Majority of breast carcinoma were of invasive ductal carcinoma, of Grade II and Stage II. No significant association was seen between the clinical behavior of a breast mass and marital status; however, malignant clinical behavior showed significant association with age. In addition, we found no association between grade and stage of breast cancer and marital status of women, suggesting that marital status has nothing to do with the prognosis of breast cancer. These results disagree with the finding of Hinyard et al., who stated that prognosis is worse in unmarried than married women with breast cancer [8]. A growing body of evidence shows that mortality following a cancer diagnosis is higher in unmarried than married patients [9-12]. However, studies on the association specific to breast cancer are limited $[13,14]$. Two main pathways have been proposed to explain the benefits of marital status on cancer and overall longevity: Better economic resources and greater social support [15]. However, these two factors need to be investigated in our community. In one large sample study, the percentage of women who reported symptoms (of total screened) increased clearly by the age of the women, $21.8 \%$ in age group of $50-54$ years and $30 \%$ in age group of 65-69 years, respectively [16].

Primary breast cancer is the most common cancer afflicting women (incidence of 1/8-10), and it is the second leading cause of cancer death overall (following lung cancer) [17]. Breast cancer which is detected early is curable, but it has a $10-20 \%$ chance of distant metastases occurring even 10-20 years after the initial diagnosis [18]. The most common sites of breast cancer metastasis are the bone, lungs, and liver [19]. Worldwide, breast cancer comprises $10.4 \%$ of all cancer

Table 5: Association between age and type of malignant breast lesion

\begin{tabular}{|c|c|c|c|c|c|c|}
\hline Malignant lesion & $21-40$ years & 41-60 years & $>60$ years & Total & Mean age \pm SD & $\mathbf{p}$ \\
\hline CIS & 0 & 3 & 0 & 3 & $47.33 \pm 4.04$ & $0.779+$ \\
\hline Invasive ductal carcinoma & 4 & 19 & 1 & 24 & $50.04 \pm 8.49$ & Not significant \\
\hline Invasive lobular carcinoma & 0 & 4 & 0 & 4 & $50.75 \pm 4.35$ & \\
\hline Medullary carcinoma & 0 & 1 & 0 & 1 & $47.00 \pm$ & \\
\hline Total & 4 & 27 & 1 & 32 & $49.78 \pm 7.58$ & \\
\hline
\end{tabular}

† Kruskal-Wallis test

Table 6: Association between age and grade of malignant breast lesion

\begin{tabular}{llllll}
\hline Grade & $\mathbf{2 1 - 4 0}$ years & $\mathbf{4 1 - 6 0}$ years & $\mathbf{> 6 0}$ years & Total & Mean age \pm SD \\
\hline I & 0 & 6 & 0 & 6 & $51.50 \pm 5.47$ \\
II & 2 & 16 & 1 & 19 & $49.79 \pm 6.89$ \\
III & 2 & 5 & 0 & 7 & $48.29 \pm 11.12$ \\
Total & 4 & 27 & 1 & 32 & Not significant \\
\hline
\end{tabular}

† Kruskal-Wallis test

Table 7: Association between age and stage of malignant breast lesion

\begin{tabular}{|c|c|c|c|c|c|c|}
\hline Stage & 21-40 years & 41-60 years & $>60$ years & Total & Mean age $\pm S D$ & $\mathbf{P}$ \\
\hline 0 & 0 & 3 & 0 & 3 & $47.33 \pm 4.04$ & $0.827 \dagger$ \\
\hline I & 0 & 5 & 0 & 5 & $50.80 \pm 3.70$ & Not significant \\
\hline II & 2 & 12 & 1 & 15 & $49.13 \pm 8.64$ & \\
\hline III & 2 & 5 & 0 & 7 & $49.29 \pm 8.98$ & \\
\hline IV & 0 & 2 & 0 & 2 & $57.50 \pm 3.54$ & \\
\hline Total & 4 & 27 & 1 & 32 & $49.78 \pm 7.58$ & \\
\hline
\end{tabular}


Table 8: Association between marital status and breast lesions

\begin{tabular}{|c|c|c|c|c|}
\hline Characteristic & Married & Not married & $\mathbf{p} \dagger$ & Significance \\
\hline \multicolumn{5}{|l|}{ Clinical behavior } \\
\hline Benign/Malignant & $120 / 30$ & $30 / 2$ & 0.064 & Not significant \\
\hline \multicolumn{5}{|l|}{ Benign lesions } \\
\hline Fibroadenoma & 49 & 19 & 0.176 & Not significant \\
\hline Fibrocystic disease & 18 & 3 & & \\
\hline Inflammatory & 38 & 6 & & \\
\hline Simple cyst & 15 & 2 & & \\
\hline CIS & 3 & 0 & 0.871 & Not significant \\
\hline Invasive ductal carcinoma & 22 & 2 & & \\
\hline Invasive lobular carcinoma & 4 & 0 & & \\
\hline Medullary carcinoma & 1 & 0 & & \\
\hline \multicolumn{5}{|l|}{ Grade } \\
\hline I & 6 & 0 & 0.548 & Not significant \\
\hline II & 18 & 1 & & \\
\hline III & 6 & 1 & & \\
\hline 0 & 3 & 0 & 0.837 & Not significant \\
\hline I & 5 & 0 & & \\
\hline II & 14 & 1 & & \\
\hline III & 6 & 1 & & \\
\hline IV & 2 & 0 & & \\
\hline
\end{tabular}

† Chi-square test" $>20 \%$ of cells have expected count $<5$ ".

incidences among women, making it the second most common type of non-skin cancer (after lung cancer) and the fifth most common cause of cancer death. In 2004, breast cancer caused 519,000 deaths worldwide ( $7 \%$ of cancer deaths; almost $1 \%$ of all deaths) [20]. Lack of effect of marital status on the incidence rate of breast cancer should open the door to search for other important environmental hazards associated with breast cancer such as radiation in the Iraqi community. There is known to be a slight increase in risk in ladies who work with low doses of radiation over a long period of time, for example, X-ray technicians [21-23].

In conclusion, the present study showed that the incidence rate of malignant breast lesions in Iraqi women with breast mass is similar to that seen worldwide and that age is the main risk factor that predicts the malignant clinical behavior of a breast mass. No association was reported between marital status and biologic behavior of breast mass, suggesting that other possible environmental factors need to be disclosed as risk factors for breast cancer in Iraqi women in addition to age.

\section{AUTHORS' CONTRIBUTIONS}

*Hassan Raji Jallab: Contributing to the study design and data interpretation, writing the manuscript, and publication. ** Marwa Abdul Hadi Hussain: Contributing to sample collection, writing the manuscript, and statistical analysis.

\section{ETHICAL CLEARANCE}

The authors certify that they have obtained all appropriate patient consent forms. In the form, the patient(s) has/have given his/her/their consent for his/her/their images and other clinical information to be reported in the journal. The patients understand that their names and initials will not be published and due efforts will be made to conceal their identity.

\section{CONFLICTS OF INTEREST}

There are no conflicts of interest.

\section{REFERENCES}

1. Zhang BN, Cao XC, Chen JY, Fu L, Hu XC, Jiang ZF. Guidelines on the diagnosis and treatment of breast cancer. Engl Surg 2012;1:39-61.

2. Shah R, Rosso K, Nathanson SD. Pathogenesis, prevention, diagnosis and treatment of breast cancer. World J Clin Oncol 2014;5:283-98.

3. Kamińska M, Ciszewski T, Łopacka-Szatan K, Miotła P, Starosławska E. Breast cancer risk factors. Prz Menopauzalny 2015;14:196-202.

4. Fathi RA, Matti LY, Al-Salih HS, Godbold D. Environmental pollution by depleted uranium in Iraq with special reference to Mosul and possible effects on cancer and birth defect rates. Med Confl Surviv 2013;29:7-25

5. Malhotra GK, Zhao X, Band H, Band V. Histological, molecular and functional subtypes of breast cancers. Cancer Biol Ther 2010;10:955-60.

6. Makki J. Diversity of breast carcinoma: Histological subtypes and clinical relevance. Clin Med Insights Pathol 2015;8:23-31.

7. Sun YS, Zhao Z, Yang ZN, Xu F, Lu HJ, Zhu ZY, et al. Risk factors and preventions of breast cancer. Int J Biol Sci 2017;13:1387-97.

8. Hinyard L, Wirth LS, Clancy JM, Schwartz T. The effect of marital status on breast cancer-related outcomes in women under 65: A SEER database analysis. Breast 2017;32:13-7.

9. Aizer AA, Chen MH, McCarthy EP, Mendu ML, Koo S, Wilhite TJ, et al. Marital status and survival in patients with cancer. J Clin Oncol 2013;31:3869-76.

10. Pinquart M, Duberstein PR. Associations of social networks with cancer mortality: A meta-analysis. Crit Rev Oncol/Hematol 2010;75:122-37.

11. Gomez SL, Hurley S, Canchola AJ, Keegan TH, Cheng I, Murphy JD, et al. Effects of marital status and economic resources on survival after cancer: A population-based study. Cancer 2016;122:1618-25.

12. Martinez ME, Anderson K, Murphy JD, Hurley S, Canchola AJ, Keegan $\mathrm{TH}$, et al. Differences in marital status and mortality by race/ethnicity and nativity among California cancer patients. Cancer 2016;122:1570-8.

13. Parikh DA, Chudasama R, Agarwal A, Rand A, Qureshi MM, Ngo T, et al. Race/ethnicity, primary language, and income are not demographic drivers of mortality in breast cancer patients at a diverse safety net academic medical center. Int J Breast Cancer 2015;83:50-74.

14. Osborne C, Ostir GV, Du X, Peek MK, Goodwin JS. The influence of marital status on the stage at diagnosis, treatment, and survival of older women with breast cancer. Breast Cancer Res Treat 2005;93:41-7.

15. Rendall MS, Weden MM, Favreault MM, Waldron H. The protective effect of marriage for survival: A review and update. Demography 2011;48:481-506.

16. Singh D, Malila N, Pokhrel A, Anttila A. Association of symptoms and breast cancer in population-based mammography screening in Finland. Int J Cancer J Int Cancer 2015;136:E630-7.

17. Selcukbiricik F, Tural D, Bay A, Sahingoz G, İlvan S, Mandel NM. A malignant mass in the breast is not always breast cancer. Case Rep Oncol 2011;4:521-5.

18. Oksuzoglu B, Abali H, Guler N, Baltali E, Ozişik Y. Metastasis to the breast from nonmammalian solid neoplasms: A report of five cases. Med Oncol 2003;20:295-300. 
19. Li HC, Patel P, Kapur P. Metastatic rectal cancer to the breast. Rare Tumors 2009; 1:e22.

20. Sharma GN, Dave R, Sanadya J, Sharma P, Sharma KK. Various types and management of breast cancer: An overview. J Adv Pharm Technol Res 2010;1:109-26.

21. Tiernan AM. The behavioral risk factor in breast cancer: Can risk be modified? Oncologist 2003;8:326-34

22. Vishnu G, Abhinabha A, Vasudha N, Santanu P. Cross-sectional study on the prevalance and risk factors of lymphoedema in carcinoma breast. Asian J Pharm Clin Res 2017;10:240-2.

23. Jayabharathi B, Blessy S. Lived in experience of women with breast cancer. Asian J Pharm Clin Res 2016;9:80-4. 